Revista Brasil. Bot., V.31, n.2, p.287-302, abr.-jun. 2008

\title{
Efeitos do substrato, bordas e proximidade espacial na estrutura da comunidade arbórea de um fragmento florestal em Lavras, MG
}

\author{
EVANDRO L.M. MACHADO 1,6 , ARY T. OLIVEIRA-FILHO', \\ EDUARDO VAN DEN BERG ${ }^{2}$, WARLEY A.C. CARVALHO 3 , JOSIVAL S. SOUZA ${ }^{4}$, \\ JOÃO J.G.S.M. MARQUES ${ }^{5}$ e NATALINO CALEGÁRIO ${ }^{1}$
}

(recebido: 24 de maio de 2007; aceito: 15 de maio de 2008)

\begin{abstract}
Effects of spatial proximity, substrate and edges on the tree community structure of a tropical forest fragment in Lavras, MG, Brazil). The present study aimed at detecting the influence of both edge effects and space substrate-related variables on the structural variations of the tree community in a small (4.0 ha) forest fragment in Lavras, Minas Gerais state, SE Brazil. Trees with diameter at breast height $(\mathrm{dbh}) \geq 5 \mathrm{~cm}$ were identified and measured in $29(20 \times 20 \mathrm{~m})$, systematically distributed plots over the fragment. Substrate-related variables were obtained for each plot from the topography, laboratory analyses of soil samples and soil compaction measures. An 'edge factor' was calculated per plot from the fragment morphometry. Spatial variables were derived from the Cartesian coordinates of plot center. A canonical correspondence analysis of the species distribution abundance indicated significant correlations with some variables of the environmental and spatial matrices. The first ones were drainage classes, mean elevation, and saturation of bases, which explained $22.4 \%$ of the total variance. The spatial variables, $\mathrm{x}$ and $\mathrm{x} 2 * \mathrm{y}$, explained $12.7 \%$, but the two sets shared, indistinctly, $4.6 \%$ of the total variance. Therefore, apart from the unexplained and stochastic variations $(69.5 \%)$, the species distribution on the fragment is primarily influenced by spatial proximity, soil nutritional status and ground water regime.
\end{abstract}

Key words - geostatistics, multivariate analysis, soils, tropical semideciduous forest, topography

RESUMO - (Efeitos do substrato, bordas e proximidade espacial na estrutura da comunidade arbórea de um fragmento florestal em Lavras, MG). Este trabalho procurou detectar a influência de efeitos de borda, espaciais e variáveis do substrato sobre as variações estruturais da comunidade arbórea de um pequeno (4,0 ha) fragmento florestal situado em Lavras, MG. Árvores com diâmetro à altura do peito $(\mathrm{DAP}) \geq 5 \mathrm{~cm}$ foram identificadas e medidas em 29 parcelas de $20 \times 20 \mathrm{~m}$, distribuídas sistematicamente por todo o fragmento. Variáveis relacionadas ao substrato foram obtidas para cada parcela a partir da topografia, análises laboratoriais de amostras do solo e medidas da compactação do solo. Um 'fator borda' foi calculado por parcela a partir da morfometria do fragmento. Variáveis espaciais foram derivadas das coordenadas cartesianas do centro das parcelas. Uma análise de correspondência canônica da distribuição da abundância das espécies indicou correlações significativas com algumas variáveis das matrizes ambiental e espacial. As primeiras foram classe de drenagem, cota média e saturação por bases, que explicaram $22,4 \%$ da variância total. As espaciais, x e x2*y, explicaram $12,7 \%$, mas os dois conjuntos compartilharam, indistintamente, $4,6 \%$ da variância total. Portanto, descontadas as variações estocásticas e não explicadas $(69,5 \%)$, a distribuição das espécies arbóreas no fragmento é primariamente influenciada pela distribuição espacial, status nutricional e regime de água dos solos.

Palavras-chave - análise multivariada, geoestatística, floresta tropical semidecídua, solos, topografia

\section{Introdução}

Em Minas Gerais, duas fisionomias de vegetação dominavam as paisagens: os cerrados, no noroeste e

1. Universidade Federal de Lavras, Departamento de Ciências Florestais, 37200-000 Lavras, MG.

2. Universidade Federal de Lavras, Departamento de Biologia, 37200000 Lavras, MG.

3. Universidade Federal de Minas Gerais, ICB, Departamento de Botânica, 30161-970 Belo Horizonte, MG.

4. Universidade Federal do Recôncavo Baiano, Centro de Ciências Agrárias, 40380-000 Cruz das Almas, BA.

5. Universidade Federal de Lavras, Departamento de Ciência do Solo, 37200-000 Lavras, MG.

6. Autor para correspondência: machadoelm@gmail.com
Triângulo, e as florestas estacionais do Domínio Atlântico, no centro-sul e leste (Veloso et al. 1991). Na realidade, a cobertura de florestas estacionais e cerrados sensu lato foram reduzidas, respectivamente, a $8,9 \% \mathrm{e}$ $7,6 \%$ de suas áreas originais (Scolforo \& Carvalho 2006). Na região do Alto Rio Grande, Sul do Estado, o processo de alteração das paisagens remonta ao início do século XVII. Hoje a cobertura vegetal original está reduzida a fragmentos, em sua maioria bastante perturbada pelo fogo, pecuária extensiva ou retirada seletiva de madeira (Oliveira-Filho \& Machado 1993). As florestas semideciduais foram drasticamente reduzidas na região, uma vez que sua ocorrência coincidia com solos mais férteis e úmidos, que são 
mais visados pela agropecuária (Oliveira-Filho et al. 1994a).

Em florestas tropicais, a qualidade nutricional do solo, a topografia, a umidade e a intensidade de luz são alguns dos fatores que mais influenciam os padrões de distribuição espacial das populações de plantas, tanto em escala regional, quanto local (Garwood 1983, Augspurger 1984, Ashton \& Hall 1992, Burslem 1996, Clark et al. 1998). A diversidade de interações entre fatores ambientais e as respectivas respostas das espécies resulta em uma heterogeneidade ambiental que determina a formação de um mosaico de habitats cujas peças podem se repetir no espaço e no tempo. Um fragmento florestal, por menor que seja, pode conter várias peças do mosaico de habitats relacionadas a diferenças de substrato, à fase sucessional e, ou ao efeito borda.

Por serem apenas derivados da floresta primordial, os fragmentos florestais podem ser amostras pouco representativas da complexidade original de habitats devido às alterações decorrentes do processo de fragmentação. A avaliação da diversidade biológica de fragmentos florestais é uma necessidade que permitirá diagnosticar, no longo prazo, as perspectivas de perdas e conservação de suas espécies.

O presente trabalho foi desenvolvido com o compartimento arbóreo de um pequeno fragmento de floresta semidecídua no município de Lavras, Minas Gerais, que, apesar de suas reduzidas dimensões, apenas 4 ha, tem seu substrato heterogêneo, incluindo duas tipologias de solo cuja distribuição não forma uma catena, isto é, não segue o sentido da encosta. O substrato é compreendido aqui como o conjunto de variáveis topográficas e de solos que determinam o status nutricional mineral e o regime de água dos solos. A hipótese básica do presente estudo é que, a despeito do tamanho reduzido do fragmento, as variações espaciais da estrutura fisionômica e da diversidade e composição de espécies de sua comunidade arbórea são afetadas pela heterogeneidade do substrato, pela influência da borda do fragmento e pelos padrões vinculados à distribuição espacial.

\section{Material e métodos}

Área de estudo - O presente estudo foi conduzido em um fragmento florestal conhecido como Mata da Lagoa e situado na Fazenda Beira Lago, Lavras, Minas Gerais, nas coordenadas de $21^{\circ} 13^{\prime} 11^{\prime \prime} \mathrm{S}$ e $44^{\circ} 58^{\prime} 15^{\prime \prime} \mathrm{W}$, com altitudes variando entre 860 e $890 \mathrm{~m}$. A área total era de cerca de 5,4 ha até 1986, quando sofreu um corte raso nas áreas da borda norte, o que reduziu sua área em 25,7\%, chegando aos atuais 4,0 ha (figura 1). A vegetação se classifica como
Floresta Estacional Semidecidual Montana (Veloso et al. 1991) e está inserida no domínio da Mata Atlântica sensu lato (Oliveira-Filho \& Fontes 2000). A Mata da Lagoa está isolada de outros fragmentos por distâncias superiores a $1 \mathrm{~km}$ e está circundada por uma matriz de baixa biomassa, com pastagens e o canal de drenagem de uma represa (na porção sul). Na borda nordeste houve corte raso para avanço das pastagens cerca de 15 anos antes do primeiro inventário (Machado et al. 2004). No interior do fragmento há sinais de exploração seletiva de madeira e da penetração do gado em busca de sombra e abrigo.

O clima é do tipo Cwb de Köppen (mesotérmico com verões brandos e suaves e estiagens de inverno). A precipitação e a temperatura médias anuais são de $1493,2 \mathrm{~mm}$ e $19,3{ }^{\circ} \mathrm{C}$, respectivamente, com $66 \%$ da precipitação ocorrendo de novembro a fevereiro (Vilela \& Ramalho 1979). Os solos foram classificados, segundo o Sistema Brasileiro de Classificação de Solo da Embrapa (2000) em duas subclasses: Argissolos Vermelho-Amarelos Distróficos (PVAd) e Nitossolos Vermelhos Eutroférricos (NVef) (Machado et al. 2004), os quais serão denominados, a partir daqui, Argissolos e Nitossolos.

Levantamento do compartimento arbóreo - Foram alocadas 29 parcelas de $20 \times 20 \mathrm{~m}$, totalizando área amostral de 1,16 ha $(29,07 \%$ do fragmento). As parcelas foram distribuídas sistematicamente em oito transeções dispostas de forma a transpor perpendicularmente o fragmento em seu sentido de maior declividade, de uma borda à outra. As distâncias foram de $30 \mathrm{~m}$ entre transeções e $10 \mathrm{~m}$ entre parcelas. Como parte de um inventário contínuo em parcelas permanentes, nos anos de 2000 e 2005, todos os indivíduos arbóreos vivos encontrados nas parcelas com diâmetro à altura do peito (DAP) $\geq 5 \mathrm{~cm}$ foram etiquetados com plaquetas de alumínio numeradas. Cada indivíduo amostrado foi identificado, sua circunferência à altura do peito (CAP) foi medida e sua altura total foi estimada conforme descrito por Machado et al. (2004).

Obtenção das variáveis ambientais e espaciais - Foi realizado levantamento topográfico da Mata da Lagoa com auxílio de um hipsômetro de Suunto para medir a inclinação do terreno. Curvas de nível eqüidistantes em $1 \mathrm{~m}$ foram traçadas com base nas cotas de pontos referenciais. As coordenadas altimétricas foram utilizadas para produzir uma representação tridimensional da área (figura 1). Quatro variáveis topográficas foram obtidas a partir dos vértices das parcelas: (a) "cota média', obtida a partir da média das quatro cotas dos vértices; (b) 'desnível', obtido pela diferença entre as cotas máxima e mínima; (c) 'distância vertical' até o curso d'água, obtida da diferença entre a cota média dos vértices e a cota do curso d'água, e (d) 'distância horizontal' até o curso d'água, obtida pela mensuração da distância do centro da parcela até margem do mesmo. Estas foram obtidas como meio de avaliação indireta do regime de água dos solos, conforme adotado por Oliveira-Filho et al. (1990, 1994b). 

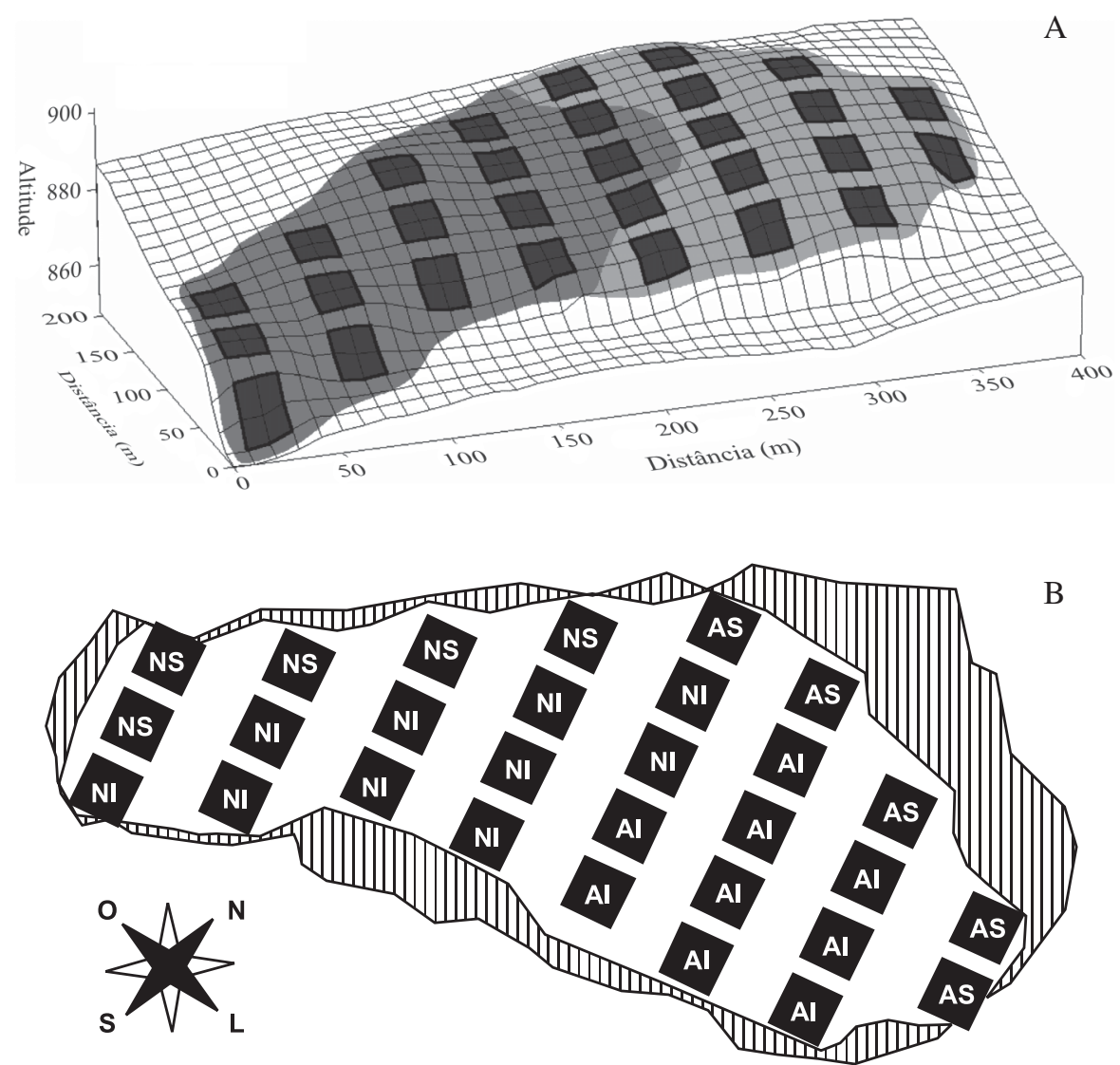

Figura 1. A. Diagrama de superfície mostrando o relevo, a distribuição das parcelas amostrais de $20 \times 20 \mathrm{~m}$ e os dois subgrupos de solos da Mata da Lagoa, Lavras (MG) ( $\square=$ Argissolo; $\square=$ Nitossolo). B. Mapa mostrando a área do fragmento florestal no período de estudo (branco), a área desmatada na década de 1980 (hachurado) e a classificação das parcelas nos quatro habitats de solo: AS = Argissolo Superior; AI = Argissolo Inferior; NS = Nitossolo Superior; NI = Nitossolo Inferior.

Figure 1. A. Surface diagram showing topography, distribution of $20 \times 20 \mathrm{~m}$ sample plots and two soil sub-groups of the Mata da Lagoa forest fragment, in Lavras, SE Brazil ( $\square=$ Argisol; $\square=$ Nitosol). B. Map showing the area of the fragment during the study period (blank), the area cleared in the 1980s (hatched) and the classification of plots into four soil habitats: AS = Upper Argisol; AI = Lower Argisol; NS = Upper Nitosol; NI = Lower Nitosol.

Para avaliar a influência da borda sobre a distribuição das espécies foi produzido um 'fator de borda' seguindo o método proposto por Oliveira-Filho et al. (1997). De posse de um mapa de distribuição das parcelas no fragmento, o 'fator de borda' de cada parcela é obtido pela medição do comprimento linear de todo contorno de borda contido no interior de um círculo cujo raio de $100 \mathrm{~m}$ tem origem no centro da parcela em questão. $\mathrm{O}$ valor do raio representaria o alcance máximo do efeito borda sobre a comunidade arbórea do interior do fragmento (Oliveira-Filho et al. 1997); quanto maior for a extensão de bordas contida no interior do círculo, maior será o efeito borda, sendo isto afetado tanto pela proximidade como pela sinuosidade da borda (Espírito-Santo et al. 2002, Botrel et al. 2002, Souza et al. 2003, OliveiraFilho et al. 2004, Dalanesi et al. 2004, Carvalho et al. 2005, Rocha et al. 2005).
Foram coletadas aleatoriamente no interior de cada parcela cinco amostras simples do solo superficial $(0-20 \mathrm{~cm})$, as quais foram misturadas e homogeneizadas para formar uma amostra composta, com cerca de $500 \mathrm{~g}$ de solo. As amostras foram enviadas para o Laboratório de Análise de Solos do Departamento de Ciências do Solo da UFLA para análises químicas e texturais, realizadas segundo o protocolo da Embrapa (1997). As variáveis de solo obtidas foram: $\mathrm{pH}$; teores de $\mathrm{P}, \mathrm{K}^{+}, \mathrm{Ca}^{++}, \mathrm{Mg}^{++}$e $\mathrm{Al}^{+++}$; soma de bases (S); saturação por bases $(\mathrm{V})$ e por alumínio $(\mathrm{m})$; e proporções de matéria orgânica, areia, silte e argila. Também foram atribuídas classes de drenagem para cada parcela, seguindo as categorias e critérios da Embrapa (2000). Combinando as características dos dois subgrupos de solo com a posição topográfica, foram encontradas três das oito classes de drenagem da Embrapa: 'moderadamente drenado', 'bem 
drenado' e 'acentuadamente drenado'. As três classes foram convertidas em uma escala ordinal de pontuação.

Para avaliar o impacto do pisoteio do gado sobre o solo e a vegetação, foram obtidas medidas da compactação do solo utilizando um penetrômetro de acordo com os procedimentos descritos por Stolf et al. (1983). Os testes de resistência à penetração foram realizados no campo para as profundidades de $0-20 \mathrm{~cm}$ e $20-40 \mathrm{~cm}$, com dez repetições distribuídas sistematicamente em cada parcela.

As variáveis topográficas e edáficas, as classes de drenagem e as medidas de compactação do solo constituíram o conjunto de variáveis relacionadas ao substrato, as quais, acrescidas do 'fator de borda', definiram o conjunto de variáveis ambientais utilizadas nas análises. As variáveis espaciais consistiram das coordenadas binárias do centro geométrico das parcelas, $\mathrm{x}$ e $\mathrm{y}$, mais sete variáveis delas derivadas $-\mathrm{x}^{2}, \mathrm{x}^{3}, \mathrm{y}^{2}, \mathrm{y}^{3}, \mathrm{x}^{*} \mathrm{y}, \mathrm{x}^{2 *} \mathrm{y}$ e $\mathrm{x}^{*} \mathrm{y}^{2}$ - seguindo o modelo polinomial proposto por Borcard et al. (1992).

Correlações entre espécies e variáveis ambientais e espaciais - Para a correlacionar as variações quantitativas das espécies arbóreas nas parcelas com variáveis ambientais e espaciais, foi adotada a análise de correspondência canônica (CCA, ter Braak 1987) executada seguindo o procedimento interativo de Borcard et al. (1992), que exige a preparação de três matrizes. As duas primeiras são as matrizes ambiental e espacial descritas anteriormente. A terceira é a matriz de espécies, que foi composta por valores de abundância das 141 espécies nas 29 parcelas. Como medida de abundância foi adotado o valor de cobertura (VC), pois este sintetiza dois parâmetros de abundância: o número de indivíduos (densidade) e sua biomassa (dominância), que expressam a ocupação do espaço comunitário pela espécie (Martins 1991, Felfili \& Rezende 2003). Os valores de densidade e área basal de cada espécie em cada parcela relativos aos da amostra total foram somados para obtenção dos VCs (Oliveira-Filho et al. 1998). Como recomendado por ter Braak (1995), os VCs foram transformados pela expressão $\ln (\mathrm{VC}+1)$ antes de se processar a análise porque suas distribuições eram tipicamente distorcidas no sentido de poucos valores muito elevados.

O passo seguinte foi a realização de quatro CCAs relacionando a matriz de espécies com (CCA1) variáveis ambientais, (CCA2) variáveis espaciais, (CCA3) variáveis ambientais e co-variáveis espaciais e (CCA4) variáveis espaciais e co-variáveis ambientais. Para tanto, foi utilizado o programa CANOCO 4.5 (ter Braak \& Smilauer 1998). Nas duas primeiras CCAs, foi utilizada a rotina de seleção progressiva de variáveis ambientais associada a testes de Monte Carlo para verificar significância das mesmas. No caso das variáveis ambientais, quatro permaneceram: classe de drenagem, cota média, saturação por bases (V) e por alumínio (m). Entre as variáveis espaciais, apenas duas foram preservadas $-\mathrm{x}$ e $\mathrm{x}^{2 *} \mathrm{y}$. As mesmas variáveis foram utilizadas nas duas outras CCAs. Testes de Monte Carlo (ter Braak 1988) foram aplicados às quatro CCAs e seus resultados foram empregados para estimar a proporção da variação dos dados das espécies que é explicada distintamente pelas variáveis ambientais e espaciais, bem como a proporção explicada indistintamente pelos dois conjuntos de variáveis e a variação remanescente que não é explicável por nenhuma das variáveis em questão.

Com base nos padrões emergentes da CCA, foram definidos quatro 'habitats de solo' combinando as três classes de drenagem e os dois subgrupos para então classificar as 29 parcelas (figura 1): Argissolo Superior (bem drenado), $n=5$; Argissolo Inferior (moderadamente drenado), $n=9$; Nitossolo Superior (acentuadamente drenado), $n=5$; e Nitossolo Inferior (bem drenado), $n=10$ parcelas. Foi utilizada a Análise de Espécies Indicadoras (Dufrêne \& Legendre 1997) processada pelo programa PC-ORD for Windows versão 4.14 (McCune \& Mefford 1999) como ferramenta na determinação das preferências das espécies pelos quatro habitats de solo. Este método combina a informação sobre a concentração da abundância de uma espécie em um certo grupo de unidades amostrais e sobre a fidelidade da ocorrência desta espécie a este mesmo grupo. Um valor indicador (ValInd) é gerado para cada espécie em cada grupo e a significância da diferença de um valor gerado pelo acaso é determinada pelo teste de permutação de Monte Carlo. Com isso, uma espécie só é considerada indicadora de um habitat quando apresenta o maior ValInd para o mesmo e o resultado do teste de Monte Carlo é significativo.

Estrutura fisionômica e diversidade de espécies - A descrição da estrutura fisionômica se baseou nas seguintes características: densidade de árvores, área basal e distribuição de diâmetros. Foram empregados intervalos de classe diamétrica com amplitudes crescentes para compensar o decréscimo da densidade nas classes de tamanhos maiores (Botrel et al. 2002).

A diversidade e riqueza de espécies arbóreas na amostra total e nos habitats foram avaliadas pelos seguintes parâmetros: riqueza de espécies, densidade de espécies por parcela e índices de diversidade de Shannon $\left(H^{\prime}\right)$ e de equabilidade de Pielou ( $\left.J^{\prime}\right)$ (Brower \& Zar 1984). A riqueza de espécies foi comparada entre os habitats por meio de curvas do esforço coletor traçadas a partir das médias e intervalos de confiança a $95 \%$ do número cumulativo de espécies, os quais foram calculados para cada tamanho amostral a partir de todas as combinações possíveis de parcelas (McCune \& Mefford 1999). Também foram calculados os estimadores 'jackknife' de primeira e segunda ordem, os quais projetam o número total de espécies a partir da heterogeneidade da amostra (Heltsche \& Forrester 1983, Palmer 1991). Os valores de $H^{\prime}$ dos habitats foram comparados pelo de $t$ de Hutcheson (Zar 1996). As comparações foram feitas aos pares porque este teste é o único disponível para comparações estatísticas entre valores de $H^{\prime}$.

Como os eventos amostrados não são espacialmente aleatórios nas parcelas, ou seja, estas não foram distribuídas independentemente, foi aplicada análise geoestatísitca para 
incorporar uma eventual dependência residual entre parcelas. As coordenadas cartesianas x e y do centro de cada parcela foram utilizadas para definir uma rede de pontos. Esta permitiu uma análise exploratória preliminar, realizada com o objetivo de observar o comportamento geral no espaço das variáveis ambientais e fisionômico-estruturais. A dependência espacial foi analisada por meio de ajuste de semivariograma utilizando-se modelos isotrópicos para testar as funções (Burrough \& McKonnell 1998).

Nos casos em que as análises variográficas indicaram que não houve estrutura espacial, ou seja, não existiu uma função estrutural com semivariância de comportamento modelável, as variáveis puderam ser analisadas por métodos clássicos de mínimos quadrados da estatística paramétrica (Zar 1996). Para realização destas análises, a normalidade das variáveis foi verificada tanto graficamente como pelo teste de Bartlett (Zar 1996). As variáveis que expressam proporções foram transformadas previamente pela função arco-seno $\sqrt{x}$. Nas comparações entre os dois grupos de solos, foram utilizados testes de $t$ de Student e, nas comparações entre os quatro habitats definidos pela combinação entre grupos de solos e classes de drenagem, foram utilizadas análises de variância seguidas de testes de Tukey-Kramer. Para isto, foi adotado um delineamento em blocos inteiramente casualizados com números de parcelas diferentes e os quatro habitats de solo como tratamentos.

\section{Resultados}

Ambiente Físico - Entre as variáveis topográficas, a cota média variou entre 856,1 e 901,7 m (média = $883,6 \mathrm{~m}$ ), o desnível dentro das parcelas entre 2,5 a $16,0 \mathrm{~m}$ (média $=6,6 \mathrm{~m}$ ), a distância vertical até o curso d'água entre 6,1 e 51,7 m (média $=33,6 \mathrm{~m}$ ) e a distância horizontal entre 19 e $91 \mathrm{~m}$ (média =53,4 m). A análise geoestatística indicou dependência espacial para as variáveis cota média, distância vertical e horizontal, efeito este já esperado uma vez que tais variáveis, são em si, de natureza espacial.

Os valores do fator borda nas 29 parcelas oscilaram entre 194,4 e 401,9 m, com média igual a $291,6 \mathrm{~m}$. O fato de o valor mínimo ser muito superior à zero indica que o fragmento não possui área interna livre de influência das bordas, dentro do critério utilizado (100 m de raio). No entanto não houve dependência espacial para o fator borda.

No caso das variáveis de solo, a análise geoestatística indicou que todas apresentaram dependência espacial quando tratadas para o fragmento como um todo, mas não quando tratadas para os dois subgrupos de solo em separado, o que reforça o caráter de solos distintos para os Nitossolos e Argissolos. Foram encontradas diferenças significativas entre os dois solos para a maioria das variáveis (tabela 1); as exceções foram o teor de argila, os níveis de $\mathrm{P}$ e $\mathrm{K}^{+}$e a resistência à penetração na profundidade de 0 a $20 \mathrm{~cm}$. Os Nitossolos apresentaram

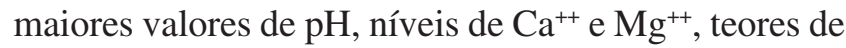
matéria orgânica e silte, soma de bases (S) e saturação por bases (V). Os Argissolos destacaram-se pelos níveis mais elevados de $\mathrm{Al}^{+++}$, saturação por alumínio (m), teores de areia e resistência à penetração na profundidade de 20 a $40 \mathrm{~cm}$. Em síntese, podemos salientar que o status nutricional global é superior no Nitossolo em comparação com o Argissolo.

Diversidade de espécies e estrutura fisionômica do compartimento arbóreo - Foram registradas 141 espécies na amostra total, sendo que os valores por habitat de solo variaram de 65, no Nitossolo Superior, a 93, no Nitossolo Inferior (tabela 2). As curvas do esforço do coletor (figura 2) e os estimadores 'jackknife' (tabela 2) indicam maior riqueza potencial para o Nitossolo Inferior, seguido pelo Argissolo Superior, Nitossolo Superior e Argissolo Inferior. Tais diferenças foram todas significativas pela análise dos intervalos de confiança (95\%) das curvas, os quais não são apresentados na figura 2 por motivo de clareza. Quando consideradas as parcelas como unidades de amostra da riqueza por

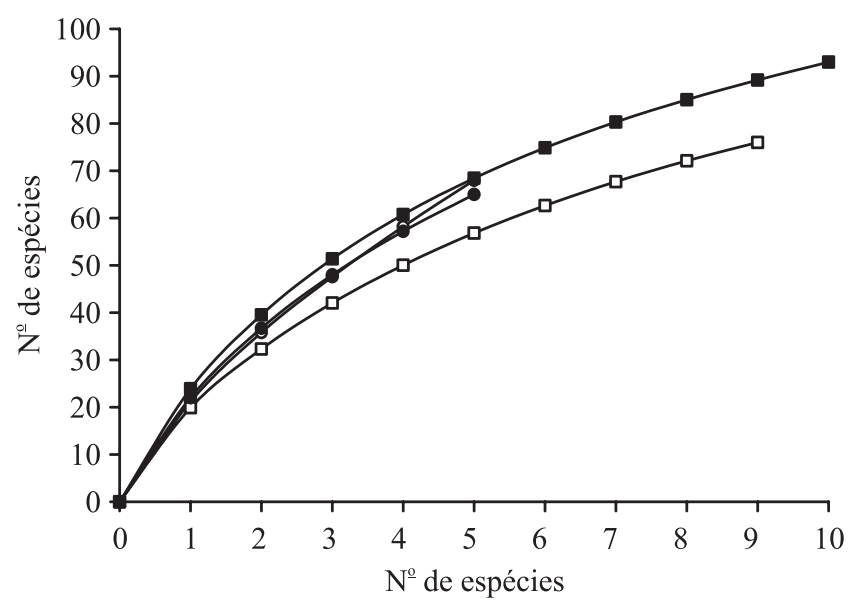

Figura 2. Curvas de progressão do número cumulativo médio de espécies com o incremento do número de parcelas amostrais (dimensões: $20 \times 20 \mathrm{~m}$ ) traçadas para os quatro habitats de solo definidos para a Mata da Lagoa, Lavras (MG) $(-\circ-=$ Argissolo Superior; $-\square-=$ Argissolo Inferior; $\bullet-=$ Nitossolo Superior; $-\mathbf{-}=$ Nitossolo Inferior).

Figure 2. Curves representing the progression of the mean cumulative number of species with increasing number of sample plots (dimensions: $20 \times 20 \mathrm{~m}$ ) drawn for the four soil habitats defined for the Mata da Lagoa forest fragment, in Lavras, SE Brazil ( $-\mathrm{O}-=$ Upper Argisol; $-\square-=$ Lower Argisol; - - = Upper Nitosol; $-\mathbf{-}=$ Lower Nitosol). 
Tabela 1. Variáveis do solo superficial $(0-20 \mathrm{~cm})$ e de resistência à penetração (profundidades de $0-20 \mathrm{~cm}$ e $20-40 \mathrm{~cm})$ nas 29 parcelas $(20 \times 20 \mathrm{~m})$ utilizadas para amostrar a Mata da Lagoa, Lavras $(\mathrm{MG})$. Os valores são médias \pm desvios padrão das $n$ amostras de cada um dos dois subgrupos de solo. As médias são comparadas por testes de $t$ de Student para amostras independentes. $* P<0,05 ; * * P<0,01 ; * * * P<0,001$; ns $=$ não significativo.

Table 1. Topsoil $(0-20 \mathrm{~cm})$ variables and soil resistance to penetration $(0-20 \mathrm{~cm}$ and $20-40 \mathrm{~cm}$ of depth) in the 29 sample plots $(20 \times 20 \mathrm{~m})$ used to survey the Mata da Lagoa forest fragment, in Lavras, SE Brazil. Values are means \pm standard deviations in $n$ samples of each soil sub-group. Means are compared with Student's $t$ tests for independent samples. $* P<$ 0,05 ; ** $P<0,01 ; * * * P<0,001 ;$ ns $=$ not significant.

\begin{tabular}{|c|c|c|c|c|}
\hline Variáveis de solo & $\begin{array}{c}\text { Argissolos } \\
n=14\end{array}$ & $\begin{array}{c}\text { Nitossolos } \\
n=15\end{array}$ & $t$ & $P$ \\
\hline \multicolumn{5}{|l|}{ Químicas: } \\
\hline $\mathrm{pH} \mathrm{em} \mathrm{H}_{2} \mathrm{O}$ & $4,75 \pm 0,22$ & $5,41 \pm 0,27$ & $-7,161$ & $* * *$ \\
\hline $\mathrm{P}-\operatorname{Mehlich}\left(\mathrm{mg} \mathrm{dm}^{-3}\right)$ & $1,14 \pm 0,36$ & $1,20 \pm 0,41$ & $-0,394$ & ns \\
\hline $\mathrm{K}^{+}\left(\mathrm{mg} \mathrm{dm}{ }^{-3}\right)$ & $48,5 \pm 28,39$ & $55,8 \pm 26,43$ & $-0,717$ & ns \\
\hline $\mathrm{Ca}^{++}\left(\mathrm{cmolc} \mathrm{dm}^{-3}\right)$ & $1,35 \pm 0,90$ & $4,06 \pm 1,24$ & $-6,710$ & $* * *$ \\
\hline $\mathrm{Mg}^{++}\left(\mathrm{cmolc} \mathrm{dm}^{-3}\right)$ & $0,68 \pm 0,54$ & $2,64 \pm 0,67$ & $-8,647$ & $* * *$ \\
\hline $\mathrm{Al}^{+++}\left(\mathrm{cmolc} \mathrm{dm}^{-3}\right)$ & $1,01 \pm 0,57$ & $0,23 \pm 0,21$ & 4,992 & $* * *$ \\
\hline 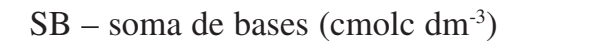 & $2,16 \pm 1,41$ & $6,83 \pm 1,64$ & $-8,175$ & $* * *$ \\
\hline $\mathrm{V}$ - saturação por bases (\%) & $22,18 \pm 14,43$ & $56,15 \pm 9,49$ & $-7,540$ & $* * *$ \\
\hline m - saturação por alumínio (\%) & $38,26 \pm 25,71$ & $3,41 \pm 3,42$ & $-5,404$ & $* * *$ \\
\hline Matéria Orgânica $\left({\left.\mathrm{dag} \mathrm{kg}^{-1}\right)}^{-1}\right.$ & $3,58 \pm 0,58$ & $4,63 \pm 0,62$ & $-4,678$ & $* * *$ \\
\hline \multicolumn{5}{|l|}{ Texturais: } \\
\hline Areia $(\%)$ & $25,28 \pm 10,28$ & $18,27 \pm 3,71$ & 2,479 & $* * *$ \\
\hline Silte $(\%)$ & $23,07 \pm 3,32$ & $29,93 \pm 4,76$ & $-4,474$ & $*$ \\
\hline Argila $(\%)$ & $51,64 \pm 9,93$ & $51,80 \pm 4,84$ & $-0,055$ & ns \\
\hline \multicolumn{5}{|l|}{ Físicas: } \\
\hline Resist. à penetração $(0-20$ cm) $(\mathrm{MPa})$ & $3,01 \pm 0,77$ & $2,70 \pm 0,46$ & 1,354 & $\mathrm{~ns}$ \\
\hline Resist. à penetração $(20-40 \mathrm{~cm})(\mathrm{MPa})$ & $5,14 \pm 0,77$ & $4,24 \pm 0,88$ & 0,773 & ** \\
\hline
\end{tabular}

área (densidade de espécies em $400 \mathrm{~m}^{2}$ ), tais diferenças desaparecem por não apresentarem diferenças significativas entre os habitats de solo.

A diferença em riqueza de espécies também foi correspondida pelo índice de diversidade de Shannon, ou $H^{\prime}$ (tabela 2), o qual foi significativamente maior no Nitossolo Inferior que em todos os demais (Argissolo Superior: $t=-3,189, P<0,010$; Nitossolo Superior: $t=-3,904, P<0,001$; e Argissolo Inferior: $t=-7,854$, $P<0,001)$. Os valores de $H^{\prime}$ no Nitossolo Superior foram significativamente maiores que no Argissolo Inferior $(t=-3,396, P<0,001)$, mas não diferiram significativamente do Argissolo Superior $(t=0,389$, $P>0,05)$. Entre os Argissolos, o valor de $H^{\prime}$ foi significativamente maior no Superior que no Inferior $(t=-3,617, P<0,001)$. Os valores da equabilidade de Pielou seguiram o mesmo padrão, decrescendo do
Nitossolo Inferior para Argissolo Superior e deste para o Nitossolo Superior e Argissolo Inferior (tabela 2), sugerindo, neste sentido, uma dominância ecológica crescente, ou seja, uma crescente concentração de abundâncias em poucas espécies.

Não foi detectada dependência espacial para nenhuma das variáveis fisionômico-estruturais tanto em análises para amostra total como para análises dos solos em separado. Não foram encontradas diferenças significativas entre as áreas basais dos quatro habitats (tabela 2). Por outro lado, as comparações entre os habitats de solo detectaram diferenças significativas para densidade absoluta das árvores, tanto quando tratadas em conjunto como em classes diamétricas, neste caso apenas para as duas menores. Para os três casos, a densidade foi significativamente maior nos dois habitats Superiores que nos dois Inferiores. Contudo, houve uma 


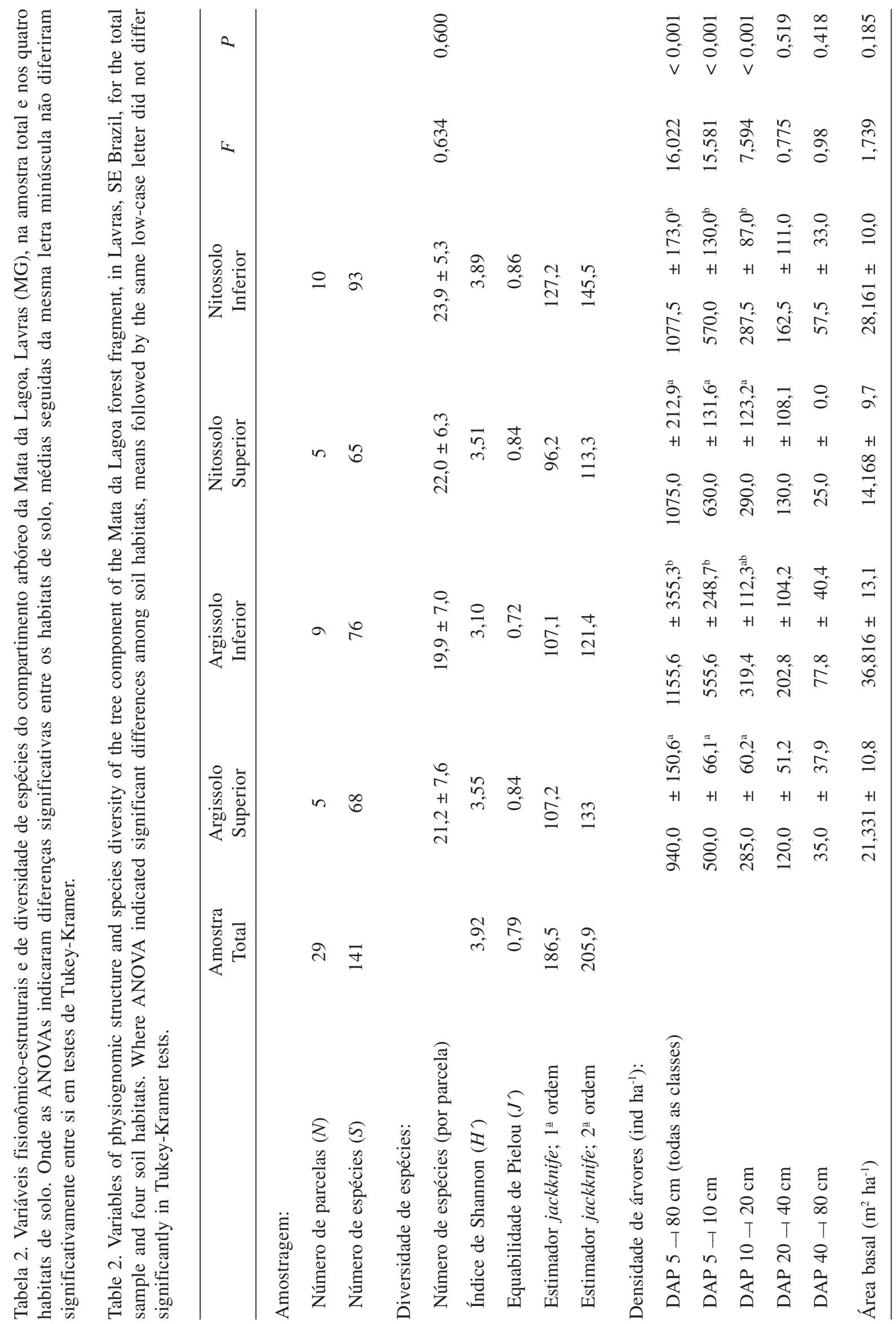


exceção: não foram detectadas diferenças significativas entre o Argissolo Inferior e os demais habitats para a segunda classe diamétrica.

Correlações entre espécies, variáveis ambientais e espaciais - As quatro CCAs apresentaram autovalores muito baixos para os dois primeiros eixos, isto é, todos $<0,30$ (tabela 3). Isto significa que os gradientes são curtos em todos os casos, ou seja, há pouca substituição de espécies e a maioria delas se distribui ao longo dos gradientes variando apenas sua abundância (ter Braak, 1995). As CCAs ambiental e espacial explicaram, respectivamente, 22,4 e $12,7 \%$ da variação total das espécies, o que salienta que, embora se trate de um pequeno fragmento, as variáveis ambientais têm peso maior que a proximidade espacial quando se procura explicar a distribuição da abundância das árvores. No entanto, apenas $17,72 \%$ da variação total é puramente ambiental e, portanto, independente do espaço (CCA3). Por outro lado, $8,10 \%$ da variação é puramente espacial e independente do ambiente (CCA4). Isto resulta que 4,64\% da variação é indistintamente espacial e ambiental (CCA1 - 3 ou CCA2 - 4), ou seja, deve-se à estrutura espacial do próprio ambiente. Em decorrência disso, pouco mais de um terço da variação total $(30,47 \%)$ foi explicada por ambiente e espaço em conjunto (CCA1 + 4 ou CCA2 + 3), restando 69,52\% de variação das espécies que é estocástica ou não explicável pelas variáveis disponíveis. Esta expressiva variância remanescente é comum em dados de vegetação e não prejudica a significância das relações espécie-ambiente (ter Braak 1988). Com efeito, as correlações de Pearson entre espécies e variáveis ambientais e espaciais foram elevadas nos dois primeiros eixos, variando entre 0,91 e 0,92 . Além disso, em todas as CCAs, os testes de permutação de Monte Carlo indicaram diferenças altamente significativas entre as correlações encontradas e as geradas pelo acaso, tanto para o primeiro eixo canônico como para o conjunto de eixos canônicos (tabela 3).

Entre as variáveis ambientais, a cota destaca-se como mais fortemente correlacionada com o segundo eixo da CCA1 e com o primeiro da CCA3 (tabela 3). A saturação por bases (V) apresentou correlações mais fortes com o primeiro eixo da CCA1. Em relação às demais, a drenagem produziu correlações mais fracas na CCA1 (ca $\pm 0,53)$, mas alcançou valor expressivo no segundo eixo da CCA3. As variáveis espaciais, $x$ e $\mathrm{x}^{2 *} \mathrm{y}$, produziram fortes correlações, entre $\pm 0,50 \mathrm{e}$ $\pm 0,85$, em todos os casos. É notório que $x$, que corresponde ao eixo leste-oeste e coincide com a dicotomia Argissolo-Nitossolo (figura 1), tenha peso bem maior na variação espacial da abundância das espécies que y, que corresponde ao eixo norte-sul e coincide com a declividade predominante na encosta.

Para representar graficamente a análise, foi escolhida a CCA1 para explorar apenas os efeitos das variáveis ambientais. Os diagramas da figura 3 mostram a ordenação de espécies e parcelas em separado, para maior clareza. As coordenadas de ordenação das espécies e parcelas representam o ótimo aproximado de uma distribuição unimodal das mesmas no espaço multidimensional definido pelas variáveis ambientais. Estas, por sua vez, são representadas por retas divergentes indicando a direção predominante da magnitude crescente de cada variável no espaço de ordenação (ter Braak 1988).

A ordenação separou com clareza as parcelas de acordo com seus habitats de solo, concentrando os Nitossolos na porção superior direita e os Argissolos na inferior esquerda, além de dispor os habitats Superiores no lado direito e os Inferiores no esquerdo (figura 3A). A separação entre os dois subgrupos de solo também correspondeu ao crescimento da saturação por bases (V) no sentido dos Nitossolos. Desta maneira, os padrões indicados pela CCA são muito coerentes com o gradiente de fertilidade crescente dos Argissolos para os Nitossolos que foi evidenciada nas análises de suas propriedades (tabela 1). Além disso, as classes de drenagem aumentam coerentemente na direção dos habitats Superiores. Os gradientes de status nutricional e regime de água nos solos são, em parte, coincidentes, o que torna difícil discriminar a relevância de cada um para a distribuição de espécies.

A ordenação das espécies pela CCA (figura 3B) sugere que as espécies Trichilia pallida, Strychnos brasiliensis, Coutarea hexandra, Allophylus edulis, Machaerium stipitatum, Maytenus ilicifolia e Dendropanax cuneatus tenderam a apresentar maior abundância nos solos de status nutricional mais elevado e maior disponibilidade de água. Nos solos de fertilidade elevada e drenagem acentuada abundam Alseis floribunda, Piptadenia gonoacantha, Acacia polyphylla, Albizia polycephala, Machaerium villosum, Tapirira obtusa, Ocotea laxa, Siparuna guianensis e Inga striata. No extremo de solos mais pobres e drenagem acentuada predominam Metrodorea stipularis, Galipea jasminiflora, Eugenia acutata e Rollinia laurifolia. Nos solos de fertilidade mais baixa e maior disponibilidade de água predominam Ocotea odorifera, Eugenia widgrenii, Ixora brevifolia, Bauhinia longifolia e Persea major.

Das 141 espécies analisadas pelo método das espécies indicadoras (tabela 4), apenas $16(11,4 \%)$ apresentaram preferência significativa por um dos habitats de solo, 


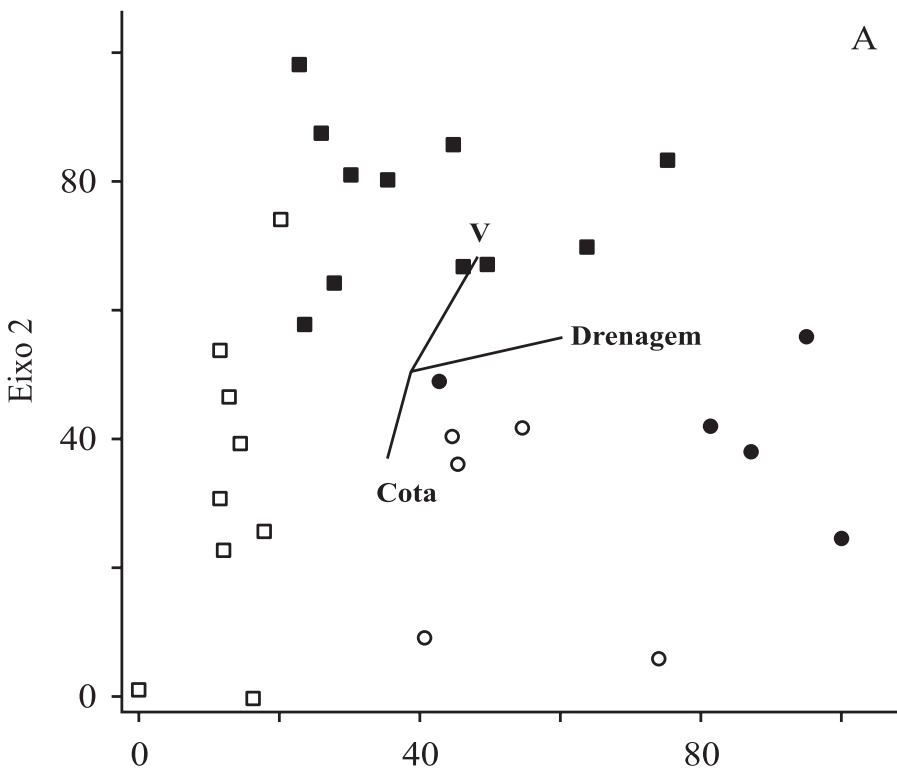

Eixo 1

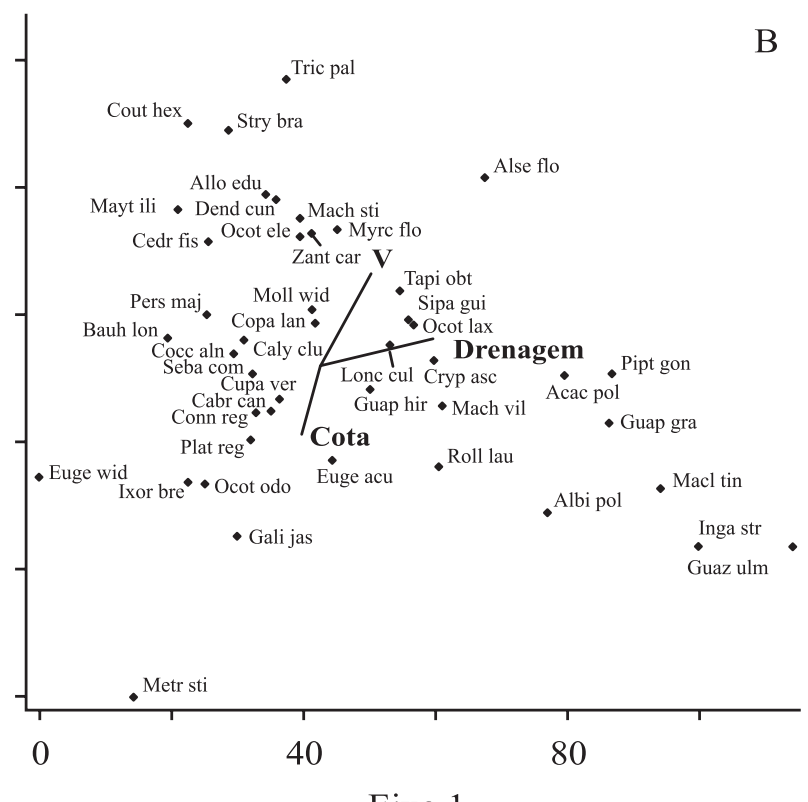

Eixo 1

Figura 3. Análise de correspondência canônica (CCA). A. Diagrama de ordenação das parcelas ( $\mathrm{O}=$ Argissolo Superior; $\square=$ Argissolo Inferior; $\bullet=$ Nitossolo Superior; $\mathbf{\square}=$ Nitossolo Inferior; V = saturação por bases). B. Diagrama de ordenação das espécies nos dois primeiros eixos da CCA baseada nas abundâncias de 39 espécies em 29 parcelas utilizadas para amostrar a Mata da Lagoa, Lavras (MG), e sua correlação com as quatro variáveis ambientais (retas convergentes). Os habitats de solo das parcelas são identificados em A e os nomes das espécies são abreviados em B: Acac pol = Acacia polyphylla, Albi pol = Albizia polycephala, Allo edu = Allophylus edulis, Alse flo = Alseis floribunda, Bauh lon $=$ Bauhinia longifolia, Cabr can = Cabralea canjerana, Caly clu = Calyptranthes clusiifolia, Cedr fis = Cedrela fissilis, Cocc aln = Coccoloba alnifolia, Conn reg = Connarus regnellii, Copa lan = Copaifera langsdorffii, Cout hex = Coutarea hexandra, Cryp asc = Cryptocarya aschersoniana, Cupa ver = Cupania vernalis, Dend cun = Dendropanax cuneatus, Euge $\mathrm{acu}=$ Eugenia acutatus, Euge wid = E. widgrenii, Gali jas = Galipea jasminiflora, Guap gra = Guapira graciliflora, Guap hir = Guapira hirsuta, Guaz ulm = Guazuma ulmifolia, Inga str = Inga striata, Ixor bre = Ixora brevifolia, Lonc cul = Lonchocarpus cultratus, Mach sti = Machaerium stipitatum, Mach vil = M. villosum, Macl tin = Maclura tinctoria, Mayt ili = Maytenus ilicifolia, Metr sti = Metrodorea stipularis, Moll wid = Mollinedia widgrenii, Myrc flo = Myrciaria floribunda, Ocot ele $=$ Ocotea elegans, Ocot lax $=$ O. laxa, Ocot odo $=$ O. odorifera, Pers maj $=$ Persea major, Pipt gon $=$ Piptadenia gonoacantha, Plat reg = Platycyamus regnellii, Roll lau = Rollinia laurifolia, Seba com = Sebastiania commersoniana , Sipa gui $=$ Siparuna guianensis, Stry bra $=$ Strychnos brasiliensis, Tapi obt $=$ Tapirira obtusa, Tric pal $=$ Trichilia pallida , Zant car = Zanthoxylum caribaeum.

Figure 3. Canonical correspondence analysis (CCA). A. Ordination diagrams for sample plots $(\mathrm{O}=\mathrm{Upper}$ Argisol; $\square=$ Lower Argisol; $\bullet=$ Upper Nitosol; $\mathbf{\square}=$ Lower Nitosol; V = saturation of bases). B. Ordination diagrams for species in the first two CCA axes based on the abundance of 39 species in 29 plots used to survey the Mata da Lagoa forest fragmento, in Lavras, SE Brazil, and their correlation with four environmental variables (converging arrows). Soil habitats are identified in $\mathrm{A}$ and species names are abbreviated in B: Acac pol = Acacia polyphylla, Albi pol = Albizia polycephala, Allo edu = Allophylus edulis, Alse flo = Alseis floribunda, Bauh lon = Bauhinia longifolia, Cabr can = Cabralea canjerana, Caly clu = Calyptranthes clusiifolia, Cedr fis = Cedrela fissilis, Cocc aln = Coccoloba alnifolia, Conn reg = Connarus regnellii, Copa lan = Copaifera langsdorffii, Cout hex = Coutarea hexandra, Cryp asc = Cryptocarya aschersoniana, Cupa ver = Cupania vernalis, Dend cun = Dendropanax cuneatus, Euge acu = Eugenia acutatus, Euge wid = E. widgrenii, Gali jas = Galipea jasminiflora, Guap gra = Guapira graciliflora, Guap hir = Guapira hirsuta, Guaz ulm = Guazuma ulmifolia , Inga str = Inga striata, Ixor bre = Ixora brevifolia, Lonc cul = Lonchocarpus cultratus, Mach sti = Machaerium stipitatum, Mach vil = M. villosum, Macl tin = Maclura tinctoria, Mayt ili = Maytenus ilicifolia, Metr sti = Metrodorea stipularis, Moll wid = Mollinedia widgrenii, Myrc flo = Myrciaria floribunda, Ocot ele = Ocotea elegans, Ocot lax = O. laxa, Ocot odo $=$ O. odorifera, Pers maj = Persea major, Pipt gon = Piptadenia gonoacantha, Plat reg = Platycyamus regnellii, Roll lau = Rollinia laurifolia, Seba com = Sebastiania commersoniana, Sipa gui = Siparuna guianensis, Stry bra = Strychnos brasiliensis, Tapi obt = Tapirira obtusa, Tric pal = Trichilia pallida, Zant car = Zanthoxylum caribaeum . 
Tabela 3. Resumo dos resultados das análises de correspondência canônica da abundância de 141 espécies distribuídas nas 29 parcelas $(20 \times 20 \mathrm{~m})$ utilizadas para amostrar a Mata da Lagoa, Lavras $(\mathrm{MG})$, em interação com variáveis ambientais e espaciais, e dos testes de permutação de Monte Carlo correspondentes. São fornecidos resultados para os dois primeiros eixos de ordenação.

Table 3. Summary of canonical correspondence analyses of the abundance of 141 species distributed in 29 sample plots $(20 \times 20 \mathrm{~m})$ used to sample the Mata da Lagoa forest fragment, in Lavras, SE Brazil, in interaction with environmental and spatial variables, and the corresponding Monte Carlo permutation tests. Results are given for the first two ordination axes.

\begin{tabular}{|c|c|c|c|c|c|c|c|c|c|}
\hline \multirow{2}{*}{\multicolumn{2}{|c|}{$\begin{array}{l}\text { CCAs* } \\
\text { Eixos: }\end{array}$}} & \multicolumn{2}{|c|}{ 1: Ambiente } & \multicolumn{2}{|c|}{ 2: Espaço } & \multicolumn{2}{|c|}{$\begin{array}{c}\text { 3: Ambiente - } \\
\text { Espaço }\end{array}$} & \multicolumn{2}{|c|}{$\begin{array}{l}\text { 4: Espaço - } \\
\text { Ambiente }\end{array}$} \\
\hline & & 1 & 2 & 1 & 2 & 1 & 2 & 1 & 2 \\
\hline \multicolumn{2}{|l|}{ Autovalores } & 0,254 & 0,204 & 0,258 & 0,165 & 0,211 & 0,146 & 0,153 & 0,116 \\
\hline \multicolumn{2}{|c|}{ Correlações espécie $\times$ ambiente ou espaço } & 0,909 & 0,925 & 0,922 & 0,940 & 0,946 & 0,958 & 0,962 & 0,951 \\
\hline \multicolumn{10}{|c|}{ Variância percentual cumulativa (\%) de: } \\
\hline \multicolumn{2}{|l|}{ dados das espécies } & 7,7 & 6,1 & 7,8 & 4,9 & 7,3 & 5,0 & 5,9 & 4,5 \\
\hline \multicolumn{2}{|c|}{ relações espécie $\times$ ambiente ou espaço } & 7,7 & 13,8 & 7,8 & 12,7 & 7,3 & 12,3 & 5,9 & 10,4 \\
\hline \multicolumn{2}{|c|}{ Soma de autovalores canônicos (traço) } & 0,742 & 0,422 & 0,588 & 0,269 & & & & \\
\hline \multicolumn{2}{|c|}{ Variância total explicada $(\%)$ : } & 22,4 & 27,2 & 20,3 & 25,4 & & & & \\
\hline \multicolumn{10}{|c|}{ Testes de permutação de Monte Carlo: } \\
\hline \multirow[t]{2}{*}{ Primeiro eixo canônico: } & $F$ & 1,992 & & 2,189 & & 1,731 & & 1,388 & \\
\hline & $P$ & 0,002 & & 0,002 & & 0,002 & & 0,036 & \\
\hline \multirow[t]{2}{*}{ Todos os eixos canônicos: } & $F$ & 1,727 & 1,896 & 1,402 & 1,281 & & & & \\
\hline & $P$ & 0,002 & 0,002 & 0,002 & 0,012 & & & & \\
\hline \multicolumn{10}{|c|}{ Correlações internas com os eixos $(r)$ : } \\
\hline \multicolumn{2}{|c|}{ Saturação por bases (V) } & 0,83 & $-0,11$ & & & $-0,15$ & 0,03 & & \\
\hline \multicolumn{2}{|l|}{ Cota média } & 0,43 & $-0,68$ & & & $-0,83$ & 0,33 & & \\
\hline \multicolumn{2}{|l|}{ Drenagem } & $-0,34$ & 0,53 & & & 0,32 & 0,82 & & \\
\hline \multicolumn{2}{|l|}{ Variável espacial x } & & & $-0,77$ & 0,52 & & & $-0,82$ & $-0,50$ \\
\hline \multicolumn{2}{|l|}{ Variável espacial $x^{2 *} \mathrm{y}$} & & & $-0,57$ & 0,73 & & & $-0,49$ & $-0,82$ \\
\hline
\end{tabular}

* Inércia total ou soma de todos os autovalores: 3,318 / Total inertia or addition of all autovalues: 3.318.

sendo $3(2,13 \%)$ pelo Argissolo Inferior, $5(3,55 \%)$ pelo Nitossolo Inferior e 4 espécies $(2,84 \%)$ para cada um dos habitats Superiores. Todas elas estão dispostas nos setores correspondentes aos seus respectivos habitats nos diagramas da CCA (figura 3).

\section{Discussão}

De uma maneira geral, a radiação solar e a disponibilidade de água e de nutrientes minerais são, nesta ordem, os fatores preponderantes na determinação dos padrões de distribuição de plantas ao redor do mundo (Hugget 1995). Na Mata da Lagoa, as variações da radiação solar foram avaliadas unicamente pelo efeito de borda, ao passo que os outros dois foram avaliados pelas propriedades do substrato. A hipótese nula do presente estudo de que os padrões de distribuição da estrutura fisionômica e da diversidade e composição de espécies não se correlacionam a variáveis do ambiente físico foi rejeitada no caso do substrato, mas não no do efeito borda.

Nenhuma característica da comunidade arbórea pôde ser diretamente associada à influência das bordas como um todo. Em dois fragmentos vizinhos à Mata da Lagoa, foram encontrados resultados discrepantes na associação com o efeito de borda. Na Reserva Florestal da UFLA (5,7 ha), o fator borda foi identificado como um dos mais fortemente correlacionados com a distribuição de espécies (Oliveira-Filho et al. 1997), a passo que, na Mata da Subestação, não foi encontrada 
Tabela 4. Espécies com resultados significativos na análise de espécie indicadoras (ISA) realizada com base nos quatro habitats de solo e valor de cobertura das 141 espécies (VIO = valor indicador observado; VIE = valor indicador esperado; $s=$ desvio padrão; $P=$ significância). Abundância relativa de indivíduos em cada habitat de solo (AS = Argissolo Superior; $\mathrm{AI}=$ Argissolo Inferior; NS $=$ Nitossolo Superior; NI $=$ Nitossolo Inferior). $* P<0,05 ; * * P<0,01 ; * * * P<0,001$.

Table 4. Species with significant results in the indicator species analyses (ISA) performed for the cover value of 141 species in the four soil habitats (VIO = observed cover value, VIE = expected cover value; $s=$ standard deviation; $P=$ significance). Relative abundance of individuals in each soil habitat (AS = Upper Argisol; AI = Lower Argisol; NS = Upper Nitosol; NI = Lower Nitosol). * $P<0,05 ; * * P<0,01$; *** $P<0,001$.

\begin{tabular}{|c|c|c|c|c|c|c|c|c|}
\hline \multirow{2}{*}{$\begin{array}{l}\text { Habitats de solo } \\
\text { Espécie }\end{array}$} & \multirow{2}{*}{ VIO } & \multicolumn{3}{|c|}{ VIE } & \multicolumn{4}{|c|}{ Abundância (\%) } \\
\hline & & Média & $s$ & $P$ & AS & AI & NS & NI \\
\hline \multicolumn{9}{|l|}{ Argissolos Superior - AS } \\
\hline Ocotea laxa (Nees) Mez & 58,0 & 22,6 & 8,8 & $* *$ & 56 & 4 & 13 & 26 \\
\hline Albizia polycephala (Benth.) Killip & 55,9 & 19,9 & 10,0 & $* *$ & 77 & 0 & 23 & 0 \\
\hline Guapira hirsuta (Choisy) Lundell & 41,7 & 15,6 & 8,4 & $*$ & 83 & 0 & 17 & 0 \\
\hline Guapira graciliflora (Schmidt) Lundell & 41,0 & 16,6 & 9,3 & $*$ & 82 & 0 & 18 & 0 \\
\hline \multicolumn{9}{|l|}{ Argissolos Inferior - AI } \\
\hline Eugenia widgrenii O. Berg & 51,5 & 20,6 & 9,7 & $* *$ & 0 & 86 & 14 & 0 \\
\hline Metrodorea stipularis Mart. & 42,7 & 20,2 & 10,7 & $*$ & 0 & 85 & 0 & 15 \\
\hline Coccoloba alnifolia Casar. & 40,0 & 16,4 & 9,7 & $*$ & 0 & 100 & 0 & 0 \\
\hline \multicolumn{9}{|l|}{ Nitossolos Superior - NS } \\
\hline Allophylus edulis (A.St.-Hil. et al.) Radlk. & 67,3 & 26,0 & 10,3 & $* *$ & 9 & 7 & 84 & 0 \\
\hline Dendropanax cuneatus (DC.) Decne \& Planchon & 50,0 & 23,3 & 9,8 & $*$ & 0 & 17 & 83 & 0 \\
\hline Strychnos brasiliensis (Sprengel) Mart. & 42,9 & 19,5 & 9,8 & $*$ & 0 & 14 & 86 & 0 \\
\hline Mollinedia widgrenii A. DC. & 40,6 & 30,8 & 5,4 & $*$ & 24 & 22 & 41 & 14 \\
\hline \multicolumn{9}{|l|}{ Nitossolos Inferior - NI } \\
\hline Piptadenia gonoacantha (Mart.) Macbr. & 79,1 & 24,8 & 9,9 & $* * *$ & 0 & 8 & 13 & 79 \\
\hline Inga striata Benth. & 60,7 & 20,9 & 10,5 & $* *$ & 0 & 24 & 0 & 76 \\
\hline Maclura tinctoria (L.) Steud. & 60,0 & 29,5 & 9,9 & $* *$ & 18 & 4 & 16 & 63 \\
\hline Acacia polyphylla DC. & 62,5 & 16,3 & 9,3 & $*$ & 0 & 0 & 0 & 100 \\
\hline Guazuma ulmifolia Lam. & 40,0 & 14,9 & 8,1 & $*$ & 0 & 0 & 0 & 100 \\
\hline
\end{tabular}

correlação significativa com a variável (Espírito-Santo et al. 2002), apesar de ser este o maior fragmento dos três ( 8,8 ha). Uma das diferenças importantes entre os dois fragmentos é que o substrato do primeiro é muito homogêneo, o que facilita a detecção do efeito borda, ao passo que a heterogeneidade de solos e topografia no segundo é elevada. Na Mata da Lagoa, a heterogeneidade do substrato também pode ter operado como um complicador para detecção do efeito borda. Contudo, seu tamanho reduzido e forma alongada são provavelmente um complicador adicional, pois, de acordo com os critérios adotados, o fragmento é inteiramente constituído de áreas de borda, sem nenhuma área interna claramente diferenciada (Pereira et al. 2007). Contudo, mesmo em fragmentos reduzidos é comum se encontrar um conjunto diferenciado de espécies típicas de bordas em uma faixa de não mais de $10 \mathrm{~m}$ de largura (Oliveira-Filho et al. 1997, van den Berg \& Oliveira-Filho 1999). Decorre disso que não se pode afirmar com certeza que não haja influência das bordas na distribuição das espécies da Mata da Lagoa, mas apenas que ela é mascarada pela heterogeneidade do substrato, faces de exposição na encosta e histórico de distúrbios passados, pois houve derrubada recente de parte das áreas de bordas.

Um aspecto da estrutura fisionômica da Mata da Lagoa que pôde ser parcialmente relacionado às bordas foi o adensamento de árvores finas e pequenas nos habitats Superiores. Esta diferença pode ser relacionada 
a algumas particularidades destes habitats. Em primeiro lugar, a disponibilidade de água é menor devido à elevação topográfica e às bordas mais expostas ao ambiente aberto. Estas bordas mais expostas também incrementam a penetração de luz e um ambiente relativamente mais seco e luminoso pode induzir um adensamento de árvores de menor porte (Murcia 1995, Oliveira-Filho et al. 1997, van den Berg \& Oliveira-Filho 1999). Já as bordas dos habitats Inferiores, localizadas no fundo do vale, têm maior suprimento de água e menor exposição aos ventos e à luz. Um outro efeito que não pode ser desconsiderado é que as bordas Superiores também são mais recentes que as Inferiores, pois houve aí corte raso para avanço das pastagens cerca de 15 anos antes do primeiro inventário (Machado et al. 2004). Isto pode caracterizar este trecho como estando em processo inicial de regeneração pós-distúrbio, com o típico adensamento de árvores finas (Uhl \& Murphy 1981, Parthasarathy 1991).

Ao contrário do efeito borda, foram encontradas correlações claras entre características da comunidade arbórea e as variáveis ambientais relacionadas ao substrato. A preponderância do recurso água sobre os nutrientes minerais também se mostrou nos padrões de distribuição de espécies na Mata da Lagoa, uma vez que a classe de drenagem foi relacionada ao gradiente mais forte e o status nutricional ao gradiente secundário, determinado pela dicotomia Argissolos-Nitossolos. Classes de drenagem e sub-grupos de solos definiram juntos os quatro habitats de solo. O regime de disponibilidade de água nos solos é fortemente dependente das características do solo e da topografia, podendo, variar em uma escala de poucos metros, com reflexo na distribuição das espécies de plantas (Terborgh 1992). Desta forma, muitas vezes é difícil distinguir claramente os efeitos do regime de água no solo sobre a distribuição das plantas devido à sua redundância com demais características do substrato. Mesmo o efeito de borda promove alterações abióticas; como mudanças na luminosidade, temperatura, umidade, velocidade do vento; que têm conseqüências sobre a disponibilidade de água nos solos expostos a este efeito (Murcia 1995). As florestas semideciduais ocorrem geralmente associadas a um regime estacional de chuvas com uma estação seca bem definida, donde se pode presumir que a capacidade de armazenamento de água de cada habitat tem um papel mais importante nos padrões de distribuição das espécies do que em florestas mais úmidas (Rizzini 1979). Na região do Alto e Médio Rio Grande a relação entre regime de água do solo e distribuição de espécies arbóreas tem sido amplamente documentada nos últimos anos (OliveiraFilho et al. 1997, 2004, Botrel et al. 2002, Espírito-Santo et al. 2002, Souza et al. 2003, Dalanesi et al. 2004, Rocha et al. 2005). No caso da Mata da Lagoa, o gradiente de regime de água no solo apresenta relações com o efeito de borda, a elevação do terreno e subgrupo de solo, visto que quanto mais alta a cota e maior a exposição ao efeito borda, mais os solos tendem a perder umidade (Kapos et al. 1997, Bierregard et al. 1992, Camargo \& Kapos 1995, Murcia 1995). Além disso, em uma base comparativa geral, o horizonte de acumulação dos Argissolos tende a dificultar mais a drenagem e armazenar mais água, aumentando a disponibilidade de água ao longo do ano (Resende et al. 1995).

É comum que a fertilidade química dos solos de uma catena cresça do topo para a base da encosta, o que também coincide com um aumento do conteúdo de água (Resende et al. 1988). No entanto, na Mata da Lagoa, a disposição dos Argissolos e Nitossolos não caracterizou uma catena de solos, pois a transição entre eles foi perpendicular à declividade da encosta. Esta particularidade contrasta com padrões catenários encontrados na maioria dos trabalhos feitos na região, onde drenagem e fertilidade dos solos formavam gradientes concordantes (Botrel et al. 2002, Espírito-Santo et al. 2002, Souza et al. 2003, Oliveira-Filho et al. 2004, Dalanesi et al. 2004, Carvalho et al. 2005). As diferenças encontradas no status nutricional dos Nitossolos e Argissolos estão dentro do esperado, visto que os primeiros apresentam fertilidade mais elevada e melhor estrutura física por serem originados de rochas máficas (Resende et al. 1995). No presente caso, a excepcional mancha de Nitossolos existente no campus da UFLA e imediações provém de uma intrusão de gabro (Espírito-Santo et al. 2002).

Fragmentos cujas áreas ao redor são compostas por pastagens com animais, os quais penetram nestes, normalmente implicam em prejuízos aos processos sucessionais e de regeneração da floresta devido à quebra de plântulas, pisoteio e pastoreio, bem como o favorecimento da disseminação de sementes de espécies invasoras. O estudo de Toniato \& Oliveira-Filho (2004) em Bauru foi o único encontrado na literatura procurando avaliar as conseqüências da influência do gado em floresta tropical nativa. Os autores utilizaram uma matriz de impactos (avaliando evidências como pegadas, trilhas e fezes), mas não encontraram diferenças significativas entre trechos com diferentes intensidades de uso pelo gado. No presente estudo, procurou-se uma forma de avaliação mais direta, por meio da resistência à penetração. Contudo, também não foi possível verificar, de maneira confiável, se os efeitos da circulação do gado constituem uma das forças reguladoras da estrutura da Mata da Lagoa. No entanto, este efeito certamente existe 
porque as clareiras abertas no sub-bosque pela circulação do gado são muito evidentes. Um motivo para a não detecção do efeito é que as classes de tamanho de plantas mais sensíveis a este impacto são menores que a amostrada. Outra possibilidade é que a ferramenta utilizada não tenha sido capaz de captar o efeito de forma eficiente devido à grande heterogeneidade espacial da circulação do gado. A fusão de metodologias de avaliação e a escolha apropriada do estrato vegetal impactado poderão, provavelmente, produzir resultados mais claros.

As variações espaciais do ambiente na Mata da Lagoa foram claramente correspondidas por distribuições diferenciais da abundância das espécies arbóreas, com consequiências para os padrões de diversidade. A heterogeneidade ambiental em florestas tropicais não controla diretamente a distribuição de um certo número de espécies por meio da variação espacial da disponibilidade de recursos, mas, na verdade, age sobre a exclusão competitiva, o que permite a distribuição diferencial de algumas espécies (Stevens \& Carson 2002). Desta forma, a quantidade de habitats diferentes tem influência nas abundâncias relativas de algumas espécies, embora isto não seja estático no tempo, pois varia com as fases de regeneração da floresta, além de sofrer a influência de eventos estocásticos (Pulliam 1996). A grande proporção de variação não explicada e o pequeno número de espécies significativamente identificadas como indicadoras de habitats reforça a idéia de que padrões estocásticos podem preponderar sobre os ambientais não como um agente causal, mas casual, na distribuição de espécies e na diversidade alfa, implicando no fato de a maioria delas serem, de fato, generalistas de habitats (Hubbell 2001).

De acordo com a 'Teoria da Fertilidade Intermediária dos Solos' (Tilman 1982, 1986), espera-se que ambientes físicos com disponibilidade nutricional intermediária apresentem maior diversidade que locais cujo status nutricional seja mais ou menos elevado. Já a 'Hipótese de Distúrbios Intermediários' (Connell 1978) preconiza que as florestas tropicais encontram-se submetidas a freqüentes distúrbios a partir dos quais o equilíbrio nunca é alcançado, assim o máximo de diversidade deve ocorrer em locais submetidos a intensidade, freqüência e duração intermediários, isto acrescido da real possibilidade de que as diferentes fases sucessionais possam ocorrer simultaneamente em uma dada área (Roberts \& Gilliam 1995). Pereira et al. (2007), analisando 20 fragmentos de florestas semidecíduas na região do Alto Rio Grande, verificou que os solos da Mata da Lagoa situam-se entre os três mais férteis. Isto poderia explicar a maior concentração de abundâncias em um pequeno número de espécies, as quais dominam a comunidade arbórea. O predomínio em número ou massa de poucas espécies em uma comunidade, também conhecido como dominância ecológica, não é incomum em florestas tropicais (Richards 1952, Whitmore 1990) e é marcante entre as florestas estacionais do Brasil Central sob solos de fertilidade intermediária a alta (Oliveira-Filho \& Ratter 2000). Considerando-se as variações internas da Mata da Lagoa, verifica-se que os valores de diversidade podem ser ajustados às idéias de Connell, mas refutam as de Tilman, pois os Nitossolos Inferiores, que registraram maior diversidade e riqueza de espécies que os demais habitats, também apresentam status nutricional superior e um histórico de distúrbios menos severos.

A Mata da Lagoa apresentou clara correlação entre a distribuição de espécies e as características do substrato, com ênfase na disponibilidade de água e nutrientes minerais nos solos. Apesar disso, também foi identificado um razoável montante de variância não explicada pelas variáveis ambientais utilizadas ('ruído'), e isto se deve, provavelmente, à estocasticidade dos fenômenos de estabelecimento e crescimento, embora não possamos descartar a possível existência de variáveis importantes, mas nem sempre facilmente perceptíveis ou mensuráreis, como condições de luz atuais e pretéritas e variáveis associadas à dispersão das espécies. Desta maneira conclusões sobre os padrões de distribuição de espécies face as variáveis ambientais só devem se aproximar de uma generalização após muitas repetições do mesmo padrão em diversas áreas.

Os pequenos fragmentos florestais dispersos pela paisagem, em muitas regiões do Brasil representam talvez a única forma de conservação disponível no momento atual. No entanto, estas pequenas unidades são as mais sensíveis aos efeitos da fragmentação florestal, estando mais suscetíveis à degradação. Estes pequenos mosaicos de uma unidade maior, hoje irrecuperável, resumem uma notável heterogeneidade ambiental refletida aqui de maneira pálida e imperfeita. O conhecimento dos mecanismos de geração e manutenção da diversidade, bem como dos processos ecológicos aos quais estão sujeitos é primordial para o estabelecimento de ações e políticas pertinentes de conservação e recuperação destas áreas remanescentes.

\section{Referências bibliográficas}

ASHTON, P.S. \& HALL, P. 1992. Comparisons of structure among mixed dipterocarp forests of north-western Borneo. Journal of Ecology 80:459-481. 
AUGSPURGER, C. 1984. Seedling survival of tropical tree species: interactions of dispersal distance, light-gaps, and pathogens. Ecology 65:1705-1712

BIERREGAARD JUNIOR, R.O., LOVEJOY, T., KAPOS, V., DOS SANTOS, A. \& HUTCHINGS, R. 1992. The biological dynamics of tropical rain forest fragments. Bioscience 42:859-866.

BORCARD, D., LEGENDRE, P. \& DRAPEAU, P. 1992. Partialling out the spatial component of ecological variation. Ecology 73:1042-1055.

BOTREL, R.T., OLIVEIRA-FILHO, A.T., RODRIGUES, L. \& CURI, N. 2002. Influência do solo e topografia sobre as variações da composição florística e estrutural da comunidade arbóreo-arbustiva de uma floresta estacional semidecidual em Ingaí, MG. Revista Brasileira de Botânica 25:195-213.

BROWER, J.E. \& ZAR, J.H. 1984. Field and laboratory methods for general ecology. $2^{\text {nd }}$ ed., W.M.C. Brow, Dubuque.

BURROUGH, P.A. \& MCKONNELL, R.A. 1998. Principles of geographical information systems: spatial information systems. Oxford University Press, New York.

BURSLEM, D.F.R.P. 1996. Differential responses to nutrients, shade and drought among tree seedlings of lowland tropical forest in Singapore. In The ecology of tropical forest tree seedlings (M.D. Swaine, ed.). UNESCO, Paris, p.211-244.

CAMARGOS, J.L.C. \& KAPOS, V. 1995. Complex edge effects on soil moisture and microclimate in Central Amazonian Forest. Journal of Tropical Ecology 11:208-211.

CARVALHO, D.A., OLIVEIRA-FILHO, A.T., VAN DEN BERG, E., FONTES, M.A.L., VILELA, E.A., MARQUES, J.J.G.S.M. \& CARVALHO, W.A.C. 2005. Variações florísticas e estruturais do compartimento arbóreo de uma floresta ombrófila alto-montana às margens do Rio Grande, Bocaina de Minas, MG, Brasil. Acta Botanica Brasilica 19:91-109.

CLARK, D.B., CLARK, D.A. \& READ, J.M. 1998. Edaphic variation and the mesoscale distribution of tree species in a neotropical rain forest. Journal of Ecology 86: 101-112.

CONNELL, J.H. 1978. Diversity in tropical rain forest and coral reefs. Science 199:1302-1310.

DALANESI, P.E, OLIVEIRA-FILHO, A.T. \& FONTES, M.A.L. 2004. Flora e estrutura do componente arbóreo da floresta do Parque Ecológico Quedas do Rio Bonito, Lavras, MG, e correlações entre a distribuição das espécies e variáveis ambientais. Acta Botânica Brasílica 18:737-757.

DUFRÊNE, M. \& LEGENDRE, P. 1997. Species assemblages and indicator species: the need for a flexible asymmetrical approach. Ecological Monograhs 67:345-366.

EMBRAPA 1997. Manual de métodos de análise de solo. Empresa Brasileira de Pesquisa Agropecuária, Centro Nacional de Pesquisa de Solos, Rio de Janeiro.
EMBRAPA 2000. Sistema brasileiro de classificação de solos. $2^{\text {ed }}$. Empresa Brasileira de Pesquisa Agropecuária, Rio de Janeiro.

ESPÍRITO-SANTO, F.D.B., OLIVEIRA-FILHO, A.T., MACHADO, E.L.M., SOUZA, J.S., FONTES, M.A.L. \& MARQUES, J.J.G.S.M. 2002. Variáveis ambientais e a distribuição de espécies arbóreas em um remanescente de floresta estacional semidecidual montana no campus da Universidade Federal de Lavras (UFLA), MG. Acta Botanica Brasílica 16:331-356.

FELFILI, J.M. \& REZENDE, R.P. 2003. Conceitos e métodos em fitossociologia. Universidade de Brasília, Brasília, 68p. (Comunicações técnicas florestais v.5, n.1).

GARWOOD, N.C. 1983. Seed germination in a seasonal tropical forest in Panama: a community study. Ecological Monographs 53:159-181.

HELTSCHE, J.F. \& FORRESTER, N.E. 1983. Estimating species richness using the jackknife procedure. Biometrics 39:1-12.

HUBBELL, S.P. 2001. The Unified Neutral Theory of Biodiversity and Biogeography. Monographs on Population Biology 32. Princeton University Press, New Jersey.

HUGGET, R.J. 1995. Geoecology: an evolutionary approach. Routledg, Londres.

KAPOS, V., CAMARGOS, J.L.C. \& DANDE, G. 1997. Edge related changes in environment and plant response due to forest fragmentation in Central Amazonia. In Tropical forest remnants: ecology, management and conservation of fragmented communities (W.F. Laurance \& R.O. Bierregaard, eds). The University of Chicago Press, Chicago, p.45-54.

MACHADO, E.L.M., OLIVEIRA-FILHO, A.T., CARVALHO, W.A.C., SOUZA, J.S., BORÉM, R.A.T. \& BOTEZELLI, L. 2004. Análise comparativa da estrutura e flora do compartimento arbóreo-arbustivo de um remanescente florestal na fazenda Beira Lago, Lavras, MG. Revista Árvore 28:493-510.

MARTINS, F.R. 1991. Estrutura de uma floresta mesófila. UNICAMP, Campinas.

MCCUNE, B. \& MEFFORD, M.J. 1999. Multivariate analysis of ecological data. MjM Software, Gleneden Beach.

MURCIA, C. 1995. Edge effects in fragmented forests: implications for conservation. Trends in Ecology and Evolution 10:58-62.

OLIVEIRA-FILHO, A.T. \& FONTES, M.A.L. 2000. Patterns of floristic differentiation among Atlantic forests in south-eastern Brazil, and the influence of climate. Biotropica 31:71-88.

OLIVEIRA-FILHO, A.T. \& MACHADO, J.N.M. 1993. Composição florística de uma floresta semidecídua montana, na Serra de São José, Tiradentes, Minas Gerais. Acta Botânica Brasílica 7:71-88. 
OLIVEIRA-FILHO, A.T. \& RATTER, J.A. 2000. Padrões florísticos das matas ciliares da região dos cerrados e a evolução das paisagens do Brasil Central durante Quaternário tardio. In Matas Ciliares: conservação e recuperação (R.R. Rodrigues \& H.F. Leitão-Filho, eds). EDUSP, São Paulo, p.73-89.

OLIVEIRA-FILHO, A.T., RATTER, J.A. \& SHEPHERD, G. J. 1990. Floristic composition and community structure of a central Brazilian gallery forest. Flora 184:103-117.

OLIVEIRA-FILHO, A.T., SCOLFORO, J.R.S. \& MELLO, J.M. 1994a. Composição florística e estrutura de um remanescente de floresta semidecidual montana em Lavras, MG. Revista Brasileira de Botânica 17:167-182.

OLIVEIRA-FILHO, A.T., VILELA, E.A., CARVALHO, D.A. \& GAVILANES, M.L. 1994b. Effects of soils and topography on the distribution of tree species in a tropical riverine forest in south-eastern Brazil. Journal of Tropical Ecology 10:483-508.

OLIVEIRA-FILHO, A.T., MELLO, J.M \& SCOLFORO, J.R.S. 1997. Effects of past disturbance and edges on tree community structure and dynamics within a fragment of tropical semideciduos forest in south-eastern Brazil over a five year period (1987-1992). Plant Ecology 131:45-66.

OLIVEIRA-FILHO, A.T., CURI, N., VILELA, E.A. \& CARVALHO, D.A. 1998. Effects of canopy gaps, topography and soils on the distribution of woody species in a central Brazilian deciduous dry forest. Biotropica 30:362-375.

OLIVEIRA-FILHO, A.T., CARVALHO, D.A., FONTES, M.A.L., VAN DEN BERG, E., CURI, N. \& CARVALHO, W.A.C. 2004. Variações estruturais do compartimento arbóreo de uma floresta semidecídua alto-montana na chapada das Perdizes, Carrancas, MG. Revista Brasileira de Botânica 27:291-309.

PALMER, M.W. 1991. Estimating species richness: the second-order jackknife estimator reconsidered. Ecology 72:1512-1513.

PARTHASARATHY, N. 1991. Tree diversity and distribution in undisturbed and human-impacted sites of tropical wet evergreen Forest in southern Western Ghats, India. Biodiversity and Conservation 8:1365-1381.

PEREIRA, J.A.A.; OLIVEIRA-FILHO, A.T. \& LEMOS FILHO, J.P. 2007. Environmental heterogeneity and disturbance by humans control much of the tree species diversity of Atlantic montane forest fragments in SE Brazil. Biodiversity and Conservation 16:1761-1784.

PULLIAM, H.R. 1996. Sources and sinks: empirical evidence and population consequences. Pp. 45-70. In Population dynamics in space and time (O.E. Rhodes, R.K. Chesser \& M.H. Smith, eds.). The University of Chicago Press, Chicago.

RESENDE, M., CURI, N. \& SANTANA, D.P. 1988. Pedologia e fertilidade do solo: interações e interpretações. Ministério da Agricultura, Brasília, e Universidade Federal de Lavras, Lavras.
RESENDE, M., CURI, N., REZENDE, S.B. \& CORRÊA, G.F. 1995. Pedologia: base para a distinção de ambiente. NEPUT, Viçosa.

RICHARDS, P.W. 1952. The tropical rain forest. Cambridge University Press, Cambridge.

RIZZINI, C.T. 1979. Tratado de fitogeografia do Brasil. 2o v. Aspectos sociológicos e florísticos. HUCITECEDUSP, São Paulo.

ROBERTS, M.R. \& GILLIAM, F.S. 1995. Patterns and mechanisms of plant diversity in forested ecosystems: implications for forest management. Ecological Applications 5:969-977.

ROCHA, C.T.V., CARVALHO, D.A., FONTES, M.A.L., OLIVEIRA-FILHO, A.T., VAN DEN BERG, E. \& MARQUES, J.J.G.S.M. 2005. Comunidade arbórea de um continuum entre floresta paludosa e de encosta em Coqueiral, Minas Gerais, Brasil. Revista Brasileira de Botânica 28:203-218.

SOUZA, J.S., ESPÍRITO-SANTO, F.D.B., FONTES, M.A.L., OLIVEIRA-FILHO, A.T. \& BOTEZELLI, L. 2003. Análise das variações florísticas e estruturais da comunidade arbórea de um fragmento de floresta semidecídua às margens do rio Capivari, Lavras-MG. Revista Árvore 27:185-206.

SCOLFORO, J.R.S. \& CARVALHO, L.M.T. 2006. Mapeamento e inventário da flora nativa e dos reflorestamentos de Minas Gerais. Editora UFLA, Lavras.

STEVENS, M.H.H. \& CARSON, W.P. 2002. Resource quantity, not resource heterogeneity, maintains plant diversity. Ecology Letters 5:420-426.

STOLF, R., FERNANDES, J. \& FURLANI NETO, V.L. 1983. Recomendação para o uso do penetrômetro de impacto - modelo IAA/Planalsucar - Stolf. MIC/IAA/ PNMCA-Planalsucar, São Paulo. 8p. (Série penetrômetro de impacto - Boletim, 1).

TER BRAAK, C.J.F. 1987. The analysis of vegetationenvironment relationships by canonical correspondence analysis. Vegetatio 69:69-77.

TER BRAAK, C.J.F. 1988. CANOCO - A FORTRAN program for canonical community ordination by (Partial) (Detrended) (Canonical) correspondence analysis and redundancy analysis, version 2.1 Technical report LWA-88-2, TNO, Institute of Applied Computer Science, Wageningen.

TER BRAAK, C.J.F. 1995. Ordination. In Data analysis in community and landscape ecology (R.H.G. Jongman, C.J.F. ter Braak \& O.F.R. van Tongeren, eds.). University Press Cambridge, Cambridge, p.91-173.

TER BRAAK, C.J.F. \& SMILAUER, P. 1998. CANOCO Reference manual and user's guide to Canoco for Windows: software for canonical community ordination (version 4). Microcomputer Power.

TERBORGH, J. 1992. Diversity and the tropical rain Forest. Scientific American Library, New York. 
TILMAN, D. 1982. Resource competition and community structure. Princeton University Press, New Jersey.

TILMAN, D. 1986. Evolution and differentiation in terrestrial plant communities: the importance of the soil resource: light gradient. In Community ecology (J. Diamond \& T.J. Case eds.). Harper and Row, New York, p.359-380.

TONIATO, M.T.Z. \& OLIVEIRA-FILHO, A.T. 2004. Variations in tree community composition and structure in a fragment of tropical semideciduous forest in southeastern Brazil related to different human disturbance histories. Forest Ecology and Management 198:319339.

UHL, C. \& MURPHY, P.G. 1981. Composition, structure, and regeneration of a tierra firme forest in the Amazon Basin of Venezuela. Tropical Ecology 22:219-237.
VAN DEN BERG, E. \& OLIVEIRA-FILHO, A.T. 1999. Spatial partitioning among tree species within an area of tropical montane gallery forest in south-eastern Brazil. Flora 194:249-266.

VELOSO, H.P., RANGEL FILHO, A.L.R. \& LIMA, J.C.A. 1991. Classificação da vegetação brasileira adaptada a um sistema universal. Instituto Brasileiro de Geografia e Estatística (IBGE), Rio de Janeiro.

VILELA, E.A. \& RAMALHO, M.A.P. 1979. Análise das temperaturas e precipitações pluviométricas de Lavras, Minas Gerais. Ciência e Prática 3:71-79.

WHITMORE, T.C. 1990. An introduction to tropical rain forest. Oxford University Press, Oxford.

ZAR, J.H. 1996. Biostatistical analysis. Prentice-Hall, New Jersey. 